\title{
A crise socioambiental e a urgência de uma nova economia
}

Vera Baldez Boing ${ }^{1}$

O tema apresentado sugere desafios a serem enfrentados, pensar novos caminhos a partir de uma realidade que se apresenta numa complexa rede, a globalização. Propomos um caminho que já se encontra aberto e, por isso, bastante divulgado: a solidariedade e o diálogo manifestados sempre diante de uma crise. Em especial, numa crise de dimensão socioambiental em relação direta com um modelo econômico excludente e desumanizador. A nossa proposta é contribuir e reconhecer, em contexto de formação, a possibilidade de um caminho educativo para uma nova perspectiva transformadora. Pretendemos seguir o pensamento profético do Papa Francisco e nos comprometer com uma nova abordagem social, ambiental e essencialmente econômica que conduza a uma realidade mais humanizadora e não, ao contrário, a uma economia que mata e desumaniza ${ }^{2}$. É preciso assumir olhar diferente para os problemas atuais e considerar a crise mundial ${ }^{3}$, reconhecendo "a desigualdade como a raiz dos males sociais" 4 .

A educação dialogada é um caminho concreto na reeducação do olhar, da forma de pensar e, portanto, de um novo estilo de vida. Uma autêntica conversão de atitudes em direção ao horizonte da criação, da casa comum. Uma perspectiva que aparece relacionada à condição de recriar novas relações, humanizando-se diante da construção de um novo modelo econômico, includente e integrado a toda a criação. Na verdade, propõe uma conversão ecológica como defesa da criação. Somente dessa forma podemos superar o pragmatismo utilitarista que desintegra as relações fundamentais entre o ser humano e a criação. "A educação seria ineficaz, e os seus esforços estéreis, se não se preocupar também em difundir um novo modelo relativo ao ser humano, à vida, à sociedade e à relação com a natureza". ${ }^{5}$ Uma proposta que o Papa Francisco sintetiza na sua profética ação como liderança religiosa, a significativa mudança de paradigma da sociedade. ${ }^{6}$

\section{Desafios e saídas alternativas}

Todo ser humano é chamado a uma ação libertadora. É convidado a desenvolver sua condição de ser livre e sujeito de sua história, para, então, assumir a tarefa da indagação e da busca de respostas aos desafios que a atualidade impõe. A liberdade, dom da vida criada, coloca o ser humano em relação com o outro, convocado a sair de si, a existir para viver a dinâmica de sua existência humana e histórica. Por isso, a alteridade e a liberdade são eixos que estruturam

\footnotetext{
${ }^{1}$ Doutora em Teologia pela Puc-Rio e professora da Cultura Religiosa da Puc-Rio.

2 FRANCISCO, EG 53.

${ }^{3}$ FRANCISCO, LS 137.

${ }^{4}$ FRANCISCO, EG 202.

${ }^{5}$ FRANCISCO, LS 215.

${ }^{6}$ FRANCISCO, LS, capítulo VI.
} 
o processo dinâmico entre as relações fundamentais: consigo mesmo, com o próximo com a sociedade e com a criação. Colocam-nos no movimento da saída e do encontro, dando-nos a condição de despertar para o processo de conversão da mentalidade que guarda ameaças à vida humana e do planeta.

Francisco vai à raiz da questão social e econômica quando aponta a exigência da conversão do estilo de vida, que podemos entender como um novo modo de ser e de agir que nasce do movimento de libertação da rede do mercado de consumo que aprisiona o indivíduo, impedindo-o de atuar como sujeito, livre e autônomo. Como afirma o Papa "o mercado cria um mecanismo consumista compulsivo, [...] obsessivo, reflexo subjetivo do paradigma tecnoeconômico". ${ }^{7}$ Torna-se mais do que necessária e urgente uma educação que favoreça, pelo conhecimento, um diálogo capaz de retomar o sentido da vida, sentido que orienta a abertura ao outro e ao cosmo, oferecendo ao ser humano viver experiências de fraternidade e de solidariedade. Teremos, assim, possibilidade da superação de uma consciência isolada, "autotranscendendo-se, rompendo com o individualismo e a autorreferencialidade, resgataremos a raiz que possibilita todo o cuidado dos outros e do meio ambiente". ${ }^{8}$

A organização da sociedade atual, marcada pela lógica do mercado e do consumo, condiciona o comportamento do ser humano de maneira desordenada, demarcando um estilo também desordenado no contexto em que atua como cidadão. Supõe-se, a partir dessa lógica consumista, a utilização do meio ambiente como bem de consumo, mercadoria descartável, utilitária, com alcance, inclusive, nas relações humanas, provocando prejuízos ao ambiente e à sociedade. ${ }^{9}$ Essa realidade tem consequências graves que podem ser irreversíveis à vida ecológica, caso não se promova de forma urgente caminhos de enfrentamento ao desafio que já expressa a crise socioambiental. ${ }^{10}$

Tratar do ambiente e das questões sociais de forma integrada, numa perspectiva ecológica, impôs ao Papa Francisco, como não poderia deixar de ser, a defesa dos pobres, excluídos, marginalizados e sobrantes. Por isso, a necessidade de apresentar o valor do trabalho como condição intrínseca à criação do mundo $(G n 2,15)$. Somente a título de recordação, a lgreja já ofereceu ao mundo uma orientação sobre a questão social do trabalho humano, o que para Francisco torna imprescindível a defesa em relação à vida criada do ser humano, criado para a liberdade de sua existência e do uso que faz para se desenvolver inserido na criação, a casa em que habita. É nesse horizonte que o Papa, profeticamente, coloca a apropriação indevida de grupos que detêm o poder econômico sobre a natureza e, dessa forma, sobre o próprio ser humano. Uma lógica de mercado e de consumo baseada numa economia excludente, que mata e destrói a Mãe Terra, deve ser reconduzida a uma digna administração da casa comum, uma

\footnotetext{
7 LS 203.

8 LS 208.

${ }^{9}$ LS 122.

10 LS 139.
} 
economia comunitária. ${ }^{11}$ Francisco envolve e orienta toda sua ação à tarefa de reforçar e construir novas práticas, projetos concretos que expressam uma nova rota, contrária à economia global, uma economia integrada à responsabilidade ambiental, que inclua as dimensões humanas e sociais. "Uma ecologia econômica capaz de induzir a considerar a realidade de forma mais ampla". ${ }^{12}$

O próximo, de modo especial o pobre, desperta a consciência e o sentimento de união, que nos motiva e nos fortalece no cuidado e na defesa pela vida. Despertar para a consciência coletiva e de pertença ao mundo "gera a convicção de que nós e todos os seres do universo, sendo criados pelo mesmo Pai, estamos unidos por laços invisíveis e formamos uma espécie de família universal". ${ }^{13}$ Nesse momento se faz a experiência de "uma comunhão universal e nada e ninguém fica excluído dessa fraternidade". ${ }^{14}$ Nessa perspectiva, o pobre tem lugar central, da mesma forma que a urgência em cuidar do planeta, da Casa comum, pois manifestam-se questões sociais alvejadas pelo poder econômico de dominação, que mata, exclui e gera graves atentados contra a vida do ser humano e do planeta. Francisco alerta para os desafios que o paradigma tecnocrático (tecnoeconômico) impõe à ecologia em nome do desenvolvimento. Desafios que se interligam e se integram no processo de mudança proposto pelo Papa, pois "a técnica, em si não é criticada, mas a sua extrapolação como horizonte cultural da compreensão da vida na sua totalidade e da sua convivência com os outros e com natureza". ${ }^{15}$

O Papa dedica uma abordagem elucidativa e globalizante na carta Encíclica Fratelli Tutti, sobre a importância dos Movimentos Populares no âmbito da sociedade. Faz uma articulação estrutural com a sociedade global. Especificamente, defende as ações da luta como resistência e geradora de novas capacidades diante dos limites e valores liberais em relação à economia, à comunidade internacional, a uma política de legitimação da democracia. Otimiza e sustenta como caminho na formação de um pensamento mais integrado que possibilite a solidariedade, novas relações humanas, que devolva a dignidade do trabalho e da vida. ${ }^{16}$

Importante perceber como o Papa explica as conquistas que acontecem dia a dia, na resistência, na organização e na defesa pela sobrevivência. ${ }^{17}$ "O bem, como aliás o amor, a justiça e a solidariedade não se alcançam de uma vez para sempre". ${ }^{18}$ Por isso é preciso, diante do mercado globalizado, que oferece riscos às experiências humanas, resistir e recriar, como "poetas sociais, criadores de trabalho, construtores de casa, produtores de alimentos, sobretudo para os descartados pelo mercado global". ${ }^{19}$ Sabemos que o poder econômico, que prevalece e

\footnotetext{
${ }^{11}$ FRANCISCO, discurso no II Encontro Mundial dos Movimentos Populares, Bolívia, Santa Cruz de La Sierra, 9 de julho de 2015.

12 LS 141.

13 LS 89.

14 LS 92.

${ }^{15}$ SACANNONE, J.C. O evangelho da misericórdia em espírito de discernimento, p. 66.

16 FT 163-169.

${ }^{17}$ FRANCISCO, aos participantes no encontro mundial dos Movimentos Populares, 28 de outubro de 2014.

18 FT 11.

19 FRANCISCO, discurso no II Encontro Mundial dos Movimentos Populares, Bolívia, Santa Cruz de La Sierra, 9 de julho de 2015.
} 
conduz à rejeição aos pobres, excluindo-os e abandonando-os à própria sorte, se encontra sempre presente. Francisco o descreve como as sombras de um mundo fechado que não favorecem ao bem comum, ao contrário os pobres são instrumentalizados pelo mercado global que tende à imposição de uma cultura que privilegia o poder do consumo e fortalece "interesses individuais e debilita a dimensão comunitária da existência". ${ }^{20}$ Dessa maneira, aponta ao mundo o papel que os movimentos representam no processo da libertação, da conversão e do assentamento de um novo protagonismo social. Assim, a história é reconduzida a uma nova perspectiva: no cotidiano e nas ações coletivas.

Em todos os discursos afirma a necessidade de dialogar sobre os grandes desafios impostos pelo modelo da globalização, os conflitos sociais, frutos da injustiça, que excluem da dignidade da vida grande parte da população global. O grande passo oferecido por Francisco foi descortinar os desafios que o mundo global revelou na capacidade de estender a destruição do mal estrutural a ponto de descartar o que de mais precioso recebemos, a criação. E, com ela, o ser humano. O poder econômico tem formas sutis de velar a realidade social da exclusão e do descarte, "abundam os eufemismos no mundo das injustiças [...] por detrás de um eufemismo esconde-se um delito". ${ }^{21} \mathrm{O}$ mal estrutural amplia a rede de uma invisibilidade da injustiça, que o Papa vai tratar como um "elo invisível" que, na realidade global, de forma paradoxal, reúne as diversas exclusões, tornando-as interligadas e submissas ao mesmo modelo destrutivo do capital, uma lógica intencional do lucro na exclusão social. ${ }^{22}$

Aquele fio invisível, aquela estrutura injusta que une todas as exclusões que vós padeceis, pode consolidar-se e transformar-se num chicote, num chicote existencial, que, como no Egito do Antigo Testamento, escraviza, rouba a liberdade, golpeia sem misericórdia [...] até onde o dinheiro divinizado quiser. (Francisco, aos participantes no encontro mundial dos Movimentos Populares, 05 de novembro de 2016).

\section{O caminho que liberta: educação dialogada}

A partir dos ensinamentos e atitudes que o Papa apresenta ao mundo, a realidade concreta e histórica é apresentada no horizonte de uma missão universal. Desenvolve uma proposta ousada e preenchida de esperança renovada e integrada à vida. Abre alguns caminhos, semeando com temas desafiadores às questões econômicas e sociais, além de outras. De todos os desafios, pensar sobre a crise socioambiental em relação ao cuidado da casa comum ferida pelo modelo excludente da economia, tornou-se uma meta urgente de sobrevivência. Por isso, a realidade deve ser o ponto de partida para romper e, simultaneamente, gerar novas práticas relacionais do ser humano com a criação. Relações que libertam do modelo econômico de

\footnotetext{
20 FT 12.

${ }^{21}$ FRANCISCO, aos participantes no encontro mundial dos Movimentos Populares, 28 de outubro de 2014.

${ }^{2}$ FRANCISCO, discurso no II Encontro Mundial dos Movimentos Populares, Bolívia, Santa Cruz de La Sierra, 9 de julho de 2015.
} 
consumo, que a sociedade gestou e naturalizou como identidade para a visibilidade social. O enfrentamento dessa realidade, mais do que importante, é condição na proposta de Francisco à superação do modelo excludente para um modelo que se pretenda mais justo e equilibrado, integrado às dimensões econômica, social e cultural.

A proposta é de mudança numa única visão, integrada, não homogeneizada, como afirma, ao utilizar a imagem do poliedro, "uma sociedade onde as diferenças convivem, integrando-se, enriquecendo-se e iluminando-se reciprocamente". ${ }^{23}$ Portanto, a perspectiva de Francisco é pensar um novo modelo econômico, social e cultural que garanta direitos à vida, integrados plenamente à criação. Francisco robustece o valor da história como processo ao destacar o caminho educativo na construção do protagonismo do povo.

O caminho que propomos, aliado à proposta do Papa Francisco, é o da educação de hábitos e valores que resultem em atitudes de solidariedade e de fraternidade, criando condições à nossa humanização. A proposta do diálogo na educação, como processo formador de novos valores integrados à compreensão da vida, da consciência e da responsabilidade. Confiar que podemos suscitar novas relações humanas, solidárias, desprendidas de valores individualistas, imanentistas e que se estendem às estruturas sociais. Por isso, a insistência da conversão do olhar e do coração que alcança o entendimento da realidade, de revisão do ponto de vista e do lugar onde estamos.

$\mathrm{Na}$ perspectiva de uma ecologia integrada, como resposta à crise socioambiental que privilegia os pobres, excluídos e marginalizados, na busca de fortalecer o protagonismo social ${ }^{24}$, educação dialogante e discernimento têm lugar nas diferentes expressões culturais. Será caminho na construção do novo paradigma que inclua o projeto de humanização, de fraterna comunhão universal.

\section{Reflexão}

1. Como a educação para a liberdade pode ser desenvolvida e fortalecida na construção de um novo paradigma econômico que inclua os pobres e excluídos do modelo atual?

2. De que forma podemos suscitar no cotidiano de nossas vidas experiências concretas de solidariedade que ultrapassem atos pontuais e esporádicos?

3. Como promover relações humanizadoras diante de uma sociedade de consumo que asfixia e desumaniza o ser humano, reduzindo-o à condição de mercadoria?

\section{Referências bibliográficas}

SCANNONE, Juan Carlos. O Evangelho da misericórdia em espírito de discernimento: a ética social do Papa Francisco. Brasília: Edições CNBB, 2019.

\footnotetext{
${ }^{23}$ FT 215.

${ }^{24}$ QA 27.
} 


\section{Documentos do Magistério}

FRANCISCO. Exortação Apostólica Evangelii Gaudium: sobre o anúncio do Evangelho no mundo atual. Vaticano, 2013.

. Discurso no Encontro Mundial dos Movimentos Populares, 28/10/2014.

. Discurso no Encontro Mundial dos Movimentos Populares, 09/07/2015.

. Encíclica Laudato Si: sobre o cuidado da casa comum. Vaticano, 2015.

Discurso no Encontro Mundial dos Movimentos Populares, 05/11/2016.

Exortação Apostólica pós-sinodal Querida Amazônia, 2020.

. Encíclica Fratelli Tutti, 2020. 